\title{
Exploring Peer Learning: Student to Student, Lecturer to Lecturer
}

\author{
Peter Petocz ${ }^{1}$, Michael Duke ${ }^{2}$, Ayse Bilgin ${ }^{1} \&$ Anna Reid ${ }^{2}$ \\ ${ }^{1}$ Department of Statistics, Macquarie University, Sydney, Australia \\ ${ }^{2}$ Sydney Conservatorium of Music, University of Sydney, Sydney, Australia \\ Correspondence: Peter Petocz, Department of Statistics, Macquarie University, North Ryde NSW 2109, \\ Australia. Tel: 61-2-98509174. E-mail: Peter.Petocz@mq.edu.au \\ Received: August 21, 2012 Accepted: September 24, 2012 Online Published: October 31, 2012 \\ doi:10.5539/ass.v8n14p91 URL: http://dx.doi.org/ass.v8n14p91
}

\begin{abstract}
This article explores how lecturers in statistics have adopted a model for a student peer learning project initially established in a music school. The exploration shows how disciplinary differences generate different peer learning approaches between students and how a team of lecturers has adapted a project from one discipline and institution to another. In essence, it explores the nature of peer learning from the perspective of student peers, including the extra insight that is available from the view of lecturer peers. The model is important as it focuses on peer learning that resides in informal spaces rather than within a formalised curriculum.
\end{abstract}

Keywords: peer learning, peer mentoring, organisational learning

\section{Peer Learning beyond the Curriculum}

Interacting with others - peer learning - has always been an important dimension for any learner and supports the learning opportunities provided in formal arenas such as lectures, tutorials, rehearsals and laboratory classes. Often, peer learning is associated with a variety of out-of-class activities such as group projects and assignments. Peer learning is most often studied within the curriculum, organised by lecturers and mediated by tutors (Boud et al., 2001). However, important aspects of peer learning occur outside the formal curriculum, and this has not been much investigated, particularly in the two disciplines considered here, music education and statistics education. As educators we don't really know much about what happens in peer-mediated learning beyond the curriculum (Havnes, 2008) in tertiary courses in statistics or music.

Yet with a greater focus on e-learning and electronic communication, such aspects of peer learning become more important. Students are less and less likely to attend classes in person and benefit from the lecturer's live approach and the actual class interactions. Rather, they obtain learning materials electronically, experience the classes via recordings, and build their educational experiences in the virtual world. In such a context, peer interactions beyond the formal curriculum, maybe with students in other classes (or even other disciplines), and organised by the participants themselves, become an essential component of successful learning. For tertiary educators, insight into the intention and practices of such peer interactions - even if they are outside the formal curriculum - contributes to the development of a more effective curriculum.

As lecturers, we know that such peer learning and sharing occur amongst our students, but we know little about what actually takes place. In situations where we set up and encourage peer learning programs, such as the PAL program in accounting investigated in Dobbie and Joyce (2009), we are able to obtain some knowledge about how the peer learning occurs by discussion with participants. We also have our own experiences of peer learning and sharing as we learn from each other as academics and collaborate on grant getting and article writing. The authors of this article, for instance, have shared and built on each other's project models, experiences with informal learning in different disciplines, and use of different modes of communication. However, understanding the range of ways in which students learn with and from each other in informal situations of their own devising remains an area beyond the usual experience of lecturers.

One of the few studies that has addressed this problem is by Havnes (2008), who considered "peer-mediated learning beyond the curriculum" (the title of his paper) in the context of an introductory course in the philosophy of science at a Norwegian university. He discussed the extra-institutional aspects of peer learning, giving students opportunities to get together to debate aspects of the curriculum, or maybe even reject the curriculum, while developing their own learning. He concluded that his student participants' problems were less with the 
philosophical material that they were studying, but rather with broader concerns about the context of their work and their diverse interactions with each other; as he put it, "the real problem is being a student" (p.202).

Havnes' analysis points out the importance of the role of one's identity as a student in the learning process. We have investigated empirically and theoretically the transition "from expert student to novice professional" for tertiary students generally (Reid et al., 2011), in the mathematical sciences (including statistics) in particular (Wood, Petocz \& Reid, 2012), and in the context of music (Duke \& Reid, forthcoming). Our analysis concluded that a student's identity as a student was closely tied with their conception of their discipline and of learning in that discipline, and that such conceptions could be broadened by contact with other students in peer interaction (Reid \& Petocz, 2003; Sisto \& Petocz, 2012). The interactions we studied previously were - as in other studies within the curriculum; the current projects allow us to extend the investigations to interactions that take place beyond the curriculum.

\section{Theories of Peer Learning}

Peer learning has come to have a variety of meanings across a range of different contexts. Often, it is used to describe cooperative learning involving joint projects, or a more senior student tutoring another more junior student (Slavin, 1990). Peer learning can also mean the philosophy and process behind students assessing other students (Boud, Cohen and Sampson 1999; Nagel Ebert-May, Weber and Hodder, 2005), and it can describe various forms of positive learning interactions. Reise, Samara and Lillejord (2012) have suggested that peer learning has a range of benefits that includes positive student achievement, reduction in faculty workload, and the development of generic skills. These three outcomes suggest a rather functional approach to the notion of peer learning, all focusing on some sort of defined outcome (achievement, workload reduction, employment). By contrast, Reid et al (2011) suggest that "an educational program in higher education can be seen as the start of a trajectory of professional formation which includes both the appropriation of a body of knowledge and of the history, social practices, skills and discourses that are part of the respective discipline or profession (p.3)". Hence, the forms of learning that go to build a person's professional view take place both inside and outside the regular curriculum.

In this paper we suggest that within this paradigm both students and teachers can be viewed as learners; the former are learning the discourses and social practices of the discipline they are studying, the latter are learning about the discourses and social practices of professional educators. Reid et al. (2011) also indicate that collaborative learning in the university context is often limited to only those groups in that specific situation. The concept of lecturer-to-lecturer peer learning implies a form of interprofessional learning, with "members of different professional groups [or disciplines] sharing a conception of learning and knowledge, which may be to the benefit of all for future negotiations of meaning" (p.109).

A major theoretical distinction has been made between the curriculum locations of peer learning. Boud, Cohen and Sampson (2001) defined the location of peer activities as being either formal or informal - that is, those that are defined by some sort of accrediting body, or those that are defined by the learners themselves, this latter corresponding essentially to Havnes' (2008) "beyond the curriculum". Students are given accreditation from their institution on the basis of the quality of learning demonstrated through formal assessment systems. The learning that occurs in more informal spaces does not usually contribute to the overall formal grade. However, students (and faculty) acknowledge that informal situations are likely to have an enormous overall impact in a person's professional identity. Reise's team recognised this and called for "more investigation into the complexity of interactions in peer learning" (Reise et al., 2012, p. 602). This 'complexity of interactions' demands an approach to peer learning that acknowledges the role of relational knowledge, an aspect of learning that is implicit when people interact. In one of our target disciplines for this paper, Leber (2005) instigated a peer learning process in a course for popular music. In that study, teachers were predominantly absent allowing students to work and rehearse with each other. They used mutual interactions to build the music. This acknowledgment from teachers that students had the capacity to teach each other suggests an about face for the regular forms of learning that take place in institutions. The key to the project was that the task was important to the participants.

Darling-Hammond (2008) identifies the need for teachers to listen to and learn sensitively from each other in order to focus on student learning in different situations. Peer learning in this context allows for lecturers to reflect on the range of their own teaching practices, discipline perspectives and theoretical constructs. These reflected perspectives focus on the quality of student learning which may be enhanced through different pedagogical approaches. The peer learning theory we espouse in this paper is a form of triple-loop reflection, in which lecturers engage with self, other lecturers and students. 
In the projects that we will present below - one completed (music) and one in progress (statistics), the discipline plays a role in the forms of learning that are important. For instance, for the music group, the music manuscript itself may suggest that intense collaboration is required to come to a successful conclusion; a different manuscript may indicate that intensive individual preparation is the most important requirement. For statistics students the context of the discipline affords quite different approaches, though again various tasks may require differing methods. The intense collaborative approach often used in music seems less frequent in statistical tasks, though group projects or consultancies may require such an approach (Sisto and Petocz, 2012). Likewise, the teachers involved in this study represent different disciplinary perspectives each of which has its specific demands for outcomes.

There is a practical need to look at the quality of learning that occurs in informal peer for peer spaces in higher education. Peer learning can lead to high quality learning outcomes for students even with a lower level of involvement from academics. In the context of music education, this is even more important as the one-on-one teaching environment that is typical of conservatoire training, can be financially crippling. In statistics education, the large (sometimes very large) class is the norm, and opportunities for peer learning can to some extent support the lower level of access to lecturers. In the projects that we present below, we have deliberately set up environments which will foster peer to peer or 'student for student' interactions in a predominantly informal environment. The aim was to encourage students to think about their learning in an autonomous way without the structured intervention of an authority.

The author team also comprises a set of peer learners. We are from two different universities and at each one a senior researcher is teamed with a mid-career academic. In each case, the teams were established to foster a change in learning culture in our disciplines, but also to develop the research capacity of the team. The music team devised the project initially and the statistics team has adopted and adapted the project. In this sense, the author teams have indulged in a learning process that includes collaborative grant writing, discussions involving the differences between learning in the disciplines, the ethical aspects of student collaborations, and the investigation of how peer learning can be integrated within the students' total learning environment.

\section{The Projects: Music and Statistics}

In the context of music, it is typical for instrumental students to receive individual lessons and combine knowledge developed in those lessons with practice-based ensemble experiences (Reid, 2001). However, there is very little opportunity for peer-to-peer interaction to enable students to explore variation in their learning and performance styles (Hunter, 1999). As Havnes (2008) suggests, these peer interactions could be essential in developing students' appreciation of their own artistry and those of others in their peer group. The aim of the project was to foster such peer interactions and, based on our knowledge about these interactions, develop a form of mentoring that would be appropriate to the discipline.

Two teams of music students were established, one with piano as their major study, and the other with saxophone. The student teams were provided with a series of prompt questions for their discussion: eg. How would you typically learn in a personal practice session; how would you typically go about learning from your friends?, Are your ways of learning different from each other?, How could you explain to others how you go about learning? There were two major differences between the groups, reflecting the common musical contexts in which these students perform: the pianists usually work on their own with only limited collaborative piano activities, whilst the saxophone students regularly work together for group performances. The peer activity was not based on any sort of formal enrolment and the outcomes of the group meetings and activity were not related to any form of assessment for their degree. In this way the project team thought that the students' own ideas regarding learning in their specific instrumental environment would be made apparent through the video construction.

Each group had a student facilitator who organised the meetings and did the background work to set up the recordings (and was paid as a research assistant). All students who participated were provided with a $\$ 150$ voucher for music purchases. The two music student groups had a series of discussions sessions which first teased out what learning from each other meant, then they discussed a means of communicating this to "first year students for orientation" and devised a video to express this learning. The groups then had the use of a media developer who helped to film and edit the materials developed by each group. The final products have since been shared with two incoming cohorts of students during orientation where the participants are also mentors for the new students - and also play the part of 'movie star' to the new students who recognise them from the films! The media outcomes (under the title of SCM Peer Learning) can be accessed on YouTube at http://www.youtube.com/watch?v=TJ9DApyuHMQ and http://www.youtube.com/watch?v=RXkmm7dfhbY . 
In the context of statistics, it is more usual for students to develop their learning through a graded sequence of units of study in various aspects of the discipline. Such a sequence would usually start with a first-year introductory unit presenting the general aspects of the discipline, then progress to second-year units in applied statistics and probability, and finally to a range of third-year units in areas such as linear models, design of experiments and (at Macquarie University) a 'capstone' unit in statistical consulting. The majority of students, however, take only a single introductory unit in statistics, usually due to a requirement from their major area of study (such as science, business or psychology). Formal peer-to-peer interaction plays a small role in the earlier statistics units, most often in the form of group assignments set for assessment by a lecturer or group discussion in a tutorial mediated by a tutor. The statistics education literature has examples to show that such activities are a common component of statistics courses generally (for example, Roseth, Garfield and Ben-Zvi, 2008). The aim of this project, however, was to explore how students learn statistics with and from each other in informal learning situations of their own devising.

Learning from the experience of the music project, the statistics team decided to set up three groups each with a pair of student facilitators (who are paid as research assistants). Extending the idea of peer learning to the project itself, we felt that a pair of facilitators in charge of each group would increase the chances of successful completion as each facilitator could encourage the other. Due to the very different contexts, we have set up one group at first-year level in an introductory unit in statistics, one group at second-year level in an applied statistics unit and a third group at third-year level, led by members of the statistical consulting class with participants from other third-year units. Each student participant will be given a gift voucher to thank them for their time. We are expecting that there may be differences in approaches to informal peer learning on the basis of students' background in statistics and their stage in statistics learning, and in essence, this corresponds to the differences in the music project between groups of students studying particular instruments. At the time of writing, the project groups have been briefed and prepared, and focus groups of students are currently taking place; as yet, there are no final products comparable to those of the music project.

One aspect that was implicit in the music project and has been made explicit in the statistics project is the role of the student leaders. In our project plan, they are described as student leaders, employed and paid as research assistants, but also as co-researchers and key members of the project team. There are many benefits to including them in the research team, both to them as students (gaining experience of authentic pedagogical research) and to us as academics (they are actually experiencing the peer learning processes that we wish to study). Such 'vertical' research teams have been effectively used in pedagogic research projects in the UK (Taylor et al., 2012) and Australia (Brew, 2010). In the music project, the student leaders were 'authors' of the media outcomes that they developed without specific direction from the lecturers. In the statistics project we plan to repeat this aspect and utilise the video clips as orientation material for future groups of students. However, we will also invite the student leaders to be co-authors on an academic output - a conference presentation or journal article.

\section{Discussion and Conclusion}

How is peer learning important to students? The projects described above show a special sort of peer learning. They acknowledge that learning takes place in spaces that are not formally prescribed by faculty or curriculum. The projects also demonstrate the impact of the discipline on the forms of knowledge that are important to students. An important consideration inherent in the concept of disciplinary knowledge is the manner in which that discipline impacts on the students' individual 'sense of being'. In peer learning that occurs outside a formal structure, we observe a strong contribution to the students' sense of becoming a professional in a particular area. Through the informal discussions, and the preparation of the videos for other incoming students, the participants developed (and will develop) a broader, conceptual and practical appreciation of their specific discipline. Reid and Solomonides (2007) noted this in the context of design students speaking about their learning. In that study, students' sense of 'being a designer' was entwined with their sense of 'transformation'. The evidence provided in that study, and in this one of music and statistics students, suggests that it is important for students to have opportunities to speak informally about their discipline, but to have those informal moments still residing within an overall learning context. In a similar fashion, in the context of professional businesses, Wenger (1998) suggests that workers move in and out of communities of practice where they learn the value of the specific business and their role within it.

How is peer learning important to lecturers? The object of research in these projects was the informal ways in which students learn with and from each other. But from the lecturers' point of view, there is a parallel peer learning investigation that they are carrying out, and this concerns the informal ways that academics from different disciplines and institutions can learn with and from each other. Essentially, the methodological approach for each project is a form of action research (McNiff, 2002), using the experience of participants in the 
learning and teaching process to find solutions to a practical pedagogical problem. For the lecturer teams in the two disciplines there is much benefit to be gained from the peer learning that comes from discussion between academics from disciplines that don't traditionally have any common ground, and rarely have any opportunity for collaboration. Two of the authors (a musician and a statistician) talked about the music project before its inception, and the transition from this to the statistics project; this was followed by dialogue within the discipline teams, and finally to a whole-team discussion to draw out the lessons learned from the two projects. The overall approach provides an example that all the authors will be able to draw upon in future research.

Havnes (2008) points out that academic learning is broader than the curricular learning that is mediated by lecturers, although many lecturers aim to help students become aware of this aspect of their learning. His notion of "learning beyond the curriculum" includes not only meta-knowledge about the curriculum, but also becoming and being a student - the aspect that his students claimed to be the 'real problem'. On the basis of our previous research (see Reid, et al., 2012), we would agree with this. We have investigated students' conceptions of their discipline and learning in a variety of disciplines - including music and statistics - and in each case, the broadest conceptions include the ontological aspect of becoming and being, a student of music or statistics first of all, and then a professional musician or statistician. These broadest conceptions are built on and include an understanding of the technical aspects of music or statistics, and an appreciation of disciplinary artefacts, such as musical scores or statistical models. Students become aware of the broadest conceptions of discipline and learning by making a personal connection between the discipline and their own personal or professional lives. We have found that experiences within the formal curriculum (such as class discussion or even participation in research interviews) may provoke such awareness. However, with our inter-disciplinary team of academic peer learners, we are finding evidence that student peer interaction beyond the curriculum may provide another important route to real and lasting learning.

\section{Acknowledgements}

Our thanks to the saxophone peer learning team led by Paul Zarborak, and the piano peer learning team led by Camellia Wong, and the leaders and participants in the statistics teams working currently.

The music project was supported by a Teaching Innovation and Performance Scheme grant from the University of Sydney, and the statistics project was supported by an Innovation and Scholarship Program grant from Macquarie University. Both projects obtained ethics approval from their respective university ethics committees.

\section{References}

Baker, F., \& Krout, R. (2012). Turning experience into learning: educational contributions of collaborative peer songwriting during music therapy training. International Journal of Music Education, 30(2), 133-147. http://dx.doi.org/10.1177/0255761411427103

Boud, D., Cohen, R., \& Sampson, J. (1999). Peer learning and assessment. Assessment and Evaluation in Higher Education, 24(4), 413-426. http://dx.doi.org/10.1080/0260293990240405

Boud, D., Cohen, R., \& Sampson, J. (2001). Peer learning in higher education: Learning from and with each other. London: Kogan Page.

Brew, A. (2010). An Australian perspective on undergraduate research. Council for Undergraduate Research Quarterly, 31(1), 37-42.

Darling-Hammond, L. (2008). Teacher learning that supports student learning. In Presseisen. B. (Ed.), Teaching for Intelligence (pp. 91-100, 2nd ed.). Thousand Oakes, CA: Corwin Press.

Dobbie, M., \& Joyce, S. (2008). Peer-assisted learning in accounting: a qualitative assessment. Asian Social Science, 4(3), 18-25.

Duke, M., \& Reid, A. (forthcoming). Students for students.

Havnes, A. (2008). Peer-mediated learning beyond the curriculum. Studies in Higher Education, 33(2), 193-204. http://dx.doi.org/10.1080/03075070801916344

Hunter, D. (1999). Developing peer-learning programmes in music: group presentation and peer assessment. British Journal of Music Education, 16, 51-63. http://dx.doi.org/10.1017/S0265051799000145

Jenkins, H. (2009). Confronting the challenge of participatory culture: Media education for the $21^{\text {st }}$ century. Cambridge MA: MIT Press. 
Lebler, D. (2008). Popular music pedagogy; peer learning in practice. Music Education Research, 10(2), 193-213. http://dx.doi.org/10.1080/14613800802079056

McNiff, J., \& Whitehead, J. (2002). Action research: Principles and practice. London: Routledge Falmer.

Nagel, L., Ebert-May, D., Weber, E., \& Hodder, J. (2005). Learning through peer assessment. Frontiers in Ecology and the Environment, 390-391. http://dx.doi.org/10.1890/1540-9295(2005)003[0390:LTPA]2.0.CO;2

Reid, A. (2001). Variation in the ways that instrumental and vocal students experience learning music. Music Education Research, 3(1), 25-40. http://dx.doi.org/10.1080/14613800020029932

Reid, A., \& Solomonides, I. (2007). Design students' experience of engagement and creativity. Art, Design \& Communication in Higher Education, 6(1), 27-39. http://dx.doi.org/10.1386/adch.6.1.27_1

Reid, A., Abrandt Dahlgren, M., Petocz, P., \& Dahlgren, L. O. (2011). From expert student to novice professional. New York: Springer. http://dx.doi.org/10.1007/978-94-007-0250-9

Reise, H., Samara, A., \& Lillejord, S. (2012). Peer relations in peer learning. International Journal of Qualitative Studies in Education, 25(5), 601-624. http://dx.doi.org/10.1080/09518398.2011.605078

Roseth, C., Garfield, J., \& Ben-Zvi, D. (2008). Collaboration in learning and teaching statistics. Journal of Statistic Education, 16(1). Retrieved from http://www.amstat.org/publications/jse/v16n1/roseth.pdf

Russell, J. (2009). Factors influencing undergraduate music education majors' investment in instrumental techniques courses taught by graduate student instructors. Music Education Research, 11(3), 335-348. http://dx.doi.org/10.1080/14613800903151606

Sisto, M., \& Petocz, P. (2012). Engaging students with statistics using collaborative, project-based approaches. In I. Solomonides, A. Reid, \& P. Petocz (Eds.), Engaging with Learning in Higher Education (pp. 297-317). Faringdon, UK: Libri Publishing.

Slavin, R. (1990). Co-operative learning: Theory, research and practice. Englewood Cliffs, NJ: Prentice Hall.

Taylor, P., Wilding, D., Mockridge, A., \& Lambert, C. (2012). Reinventing engagement. In I. Solomonides, A. Reid, \& P. Petocz (Eds.), Engaging with Learning in Higher Education (pp. 259-278). Faringdon UK: Libri Publishing.

Topping, K. (2005). Trends in Peer Learning. Experimental Educational Psychology, 25(6), 631-645. http://dx.doi.org/10.1080/01443410500345172

Wenger, E. (1998). Communities of Practice: Learning, meaning and identity. Cambridge, UK: Cambridge University Press. 